\title{
A Simple Though Tricky Way of Managing Dislodged Tooth under General Anaesthesia
}

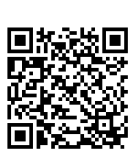

\author{
Mamta Mahobia, Meena Singh*, Mahendra S Chauhan and Rekha Mahendra \\ Department of Anaesthesia, NSCB Medical College, India
}

Submission: December 07, 2017; Published: February 05, 2018

*Corresponding author: Meena Singh, Department of Anaesthesia, N.S.C.B. Medical College, House no: 127, Nehru Nagar, opposite NSCB Medical College, Pin code: 482003, Jabalpur (MP), India,Tel: 9891583499; Email: dr.meenasingh2010@gmail.com

\begin{abstract}
Whenever patient is undergoing general anaesthesia involving larymgoscopy and intubation there is possibility of injury to oral contents especially tooth. If surgery is involving oral cavity risk becomes even higher. General anaesthesia involves end tracheal intubation, requiring laryngoscopic manipulation of mouth to expose vocal cords. Surgeries in and around the mouth which requires instrumentation in oral cavity carries additional risk of tooth injury. Although Anesthesiologist consistently uses oral route to intubate, still they may not have been exposed to a comprehensive education of tooth, surrounding tissue and prosthesis. Peroperative dental injuries are one of the most common anaesthesia related adverse events and are responsible for the greatest number of malpractice claims against anesthesiologists. The possibility of dental damage increases in patients having difficult intubation with poor oral hygiene, gross dental carries and several loose teeth. Pre anaesthetic checkup of patient's dental status including recognition of vulnerable teeth, soft tissues are important in prevention of perioperative dental damage and claims against anesthesiologists.
\end{abstract}

Keywords: Difficult Intubation; Dislodged Tooth; Suction Catheter

\section{Introduction}

A Dislodgement of a loose tooth during difficult intubation and oral surgery is a well known complication. Dental injuries account for one third of all medico legal claims against anesthesiologist. During difficult intubation chances of injury to tooth are there because of some pressure required to expose glottis by laryngoscope. To keep the mouth open during surgery of oral cavity, retractors such as crowe-davis or dig man are used. These retractors exert considerable force on patient dentition. So chances of injury are more with loose tooth.

In oral surgery both anesthesiologist and surgeon work on the same field so dislodgement of loose tooth may occur during intubation or while surgery. So before intubation or operating in oral cavity, Anesthesiologist and surgeon should be aware of any loose tooth. Although laryngoscope is a safe procedure but complication may occur and there are chances of damage to soft tissue as well hard tissue of oral cavity in patients with restricted mouth opening associated with oral pathology and presence of dental carries, loose tooth or crowns. Inability to retrieve the dislodged tooth can lead not only to cosmetic handicap but also to medical and medico legal consequences. In this article we are describing the successful retrieval of a dislodged tooth in hemiglossectomy surgery patient having difficult intubation.

\section{Case Report}

A 60 years old male patient weighing $78 \mathrm{~kg}$ posted for growth tongue due for hemiglossectomy. On preanaesthetic examination patient was having short neck, restricted mouth opening, loose lateral maxillary incisors and missing central incisor tooth. He was explained the possibility of dislodgement of loose tooth and was recorded in the pre anaesthetic form. The oral intubation was anticipated to be difficult but possible. Monitoring during procedure included electrocardiogram, non-invasive blood pressure, pulse oximetry, end tidal carbon dioxide $\left(\mathrm{EtCO}_{2}\right)$. Patient was premeditated with glycopyrrolate $0.2 \mathrm{mg}$ IV and inj fentanyl $100 \mu \mathrm{g}$ IV. Case was induced with IV propofol 100mg after adequate preoxygenation. After ensuring adequate mask ventilation $100 \mathrm{mg}$ succinylcholine was given to facilitate tracheal intubation. Laryngoscopy was difficult because of restricted mouth opening and only epiglottis was visualized. Two attempts of oral intubation was failed and trachea was intubated in third attempt using McCoy blade No. 3. Since it was a case of oral surgery so throat packing was done to prevent aspiration or soiling of lungs with oral blood. Inspite of difficult intubation we tried our best to preserve all loose teeth [1-7]. At the end of operation when we were preparing for laryngoscopy to remove throat pack we noticed absence of one tooth from upper left incisor side. As the 
operation was over and patient was recovering from anaesthesia, patient was again sedated with i.v. propofol $50 \mathrm{mg}$ to permit laryngoscopy and search was made for dislodged tooth in oral cavity but we could not find it. Tooth was intact and in place at the end of intubation and throat packing so there were chances of dislodgement of tooth in oral cavity during hemiglossectomy surgery.

As to facilitate surgery, head was extended by keeping pillow under shoulders so speculating that dislodged tooth could have migrated into nasopharynx, we introduced suction catheter through nasal route. The tooth was pushed from nasopharynx to oropharynx with the help of suction catheter and then removed with the help of Magill forceps. Using suction catheter through nasal route for retrieving of dislodged tooth from nasopharynx is the easiest available method in operation theatre. There are case reports of searching dislodged tooth by nasal or oral fibreoptic scope and fluoroscopy.

\section{Discussion}

Since dental damage or dislodgement of loose tooth is one of the most likely adverse outcome during general anesthesia and more so in oral surgeries where anesthesiologist and surgeon both work in oral cavity, it is recommended that the patient be made aware of this possibility during the preanesthetic evaluation, specially with an anticipated difficult intubation and/ or a patient's vulnerable preexisting dentition like loose tooth, unstable crowns, bridge work and intraoral prosthesis (Dentures or orthodontic appliances) documentation of the patient's preanesthetic dental condition and informing the patient about the potential dental damage can substantially decrease the likelihood of uninformed, unprepared or angry patient postoperatively.

It should be noted that it is not always the anesthesiologist who is responsible for dental damage in the operation theatre, surgeons such as otolaryngologists may cause such an injury during application of mouth gag, rigid laryngoscope, bronchoscope, oesophagoscope. Determining which practitioner was directly involved with the dental trauma is suggested before the discussion with the patient. Once the patient is fully awake a discussion of the perioperative dental incidence should be done. In the perioperative period majority of dental injuries occur during tracheal intubation. When a satisfactory view of glottis is difficult to obtain during laryngoscopy, the patient's maxillary anterior teeth are used as a fulcrum by laryngoscope (residence and trainee anesthetists) blade to obtain better view. Consequently the maxillary incisors, particularly the left central incisors are damaged most frequently. Anterior teeth such as incisors are single rooted with a forward dental axis and a small cross sectional area, rendering them susceptible to trauma when a vertical and/or an oblique force is applied to them. Posterior teeth, such as molars, have multiple roots and a wider cross sectional area and much better equipped to with stand such forces.

Apart from laryngoscopy dental damage can be caused by other events like aggressive suctioning in the posterior of mouth, oropharyngeal airway placement subjecting anterior teeth to extreme lateral forces and biting down vigorously upon endotracheal tube or laryngeal mask airway shaft in situ during emergence from anesthesia. Other provocative events include the forceful removal of an oral airway, endotrachal tube or LMA upon emergence and shivering during recovery phase, which may cause spasm of the masseter muscle leading to excessive pressure while clenching and/ or grinding the teeth. The usual attributes for dislodgement of tooth during laryngoscopy or surgery are operator's inexperience, inattention and inadequate supervision during intubation and surgery. In our patient too, these were the main causes. Expert operator's skills and compliance are mandatory to prevent the complication.

\section{Recommendations}

Since laryngoscopy or any other instrumentation in oral cavity is the most common procedure that may lead to dental damage, prevention of such an injury during this time warrants particulars attention. During anesthesia proper relaxation with adequate dose of muscle relaxant is must. A technique involving gentle blade placement and motion, along with carefully applied forces, should be used. Triple maneuver (i.e. head tilt, chin lift and jaw thrust) should be used for opening the mouth and minimizing the contact with teeth. Patient with Mallampati score of 3 and prominent buck teeth have been reported to experience blade tooth contact $>90 \%$ of intubations, prompting the modification of laryngoscope blade to avoid dental damage e.g. "The dental protector blade" "improved laryngoscope blade" or "Callender laryngoscope blade". Direct laryngoscopy using paraglossal straight blade technique avoids dental damage in patients with loose upper incisors having difficult intubation.

Two types of dental shield have been developed to reduce the force applied to the teeth and potential probability of tooth damage during laryngoscopy. One of these consists of individually adaptable shield using thermoplastic material, cellulose acetate foil or ethylene vinyl acetate. The other group is preformed dental shield. Costom mouth guards can be useful to decrease force of laryngoscope affecting the upper central incisors. Dentasafe is a device that has been designed to minimize the risk of chipping the incisors during intubation. It consists of an adherent piece of foam that is attached to an laryngoscope preventing direct force on incisors. For surgeries in and around mouth, dental guards can be used to reduce the risk of tooth injury. Before surgery a costom dental guard can be prepared by dentist and even surgeon can prepare this guard by using aqua last splint.

So finally this is the recommendation that in routine preanesthetic check up Anesthesiologist must assess properly the dental condition of the patient. Any artificial teeth, loose teeth should be removed before inducing the patient for surgery. Teeth that are loose but should be saved can be splinted (joined) together to improve their strength and prevent aspiration during intubation and surgery. For prevention of dislodgment of loose tooth we can tie a piece of silk or thread around the base of loose tooth and then both free ends of thread brought out of the patients 
mouth together and taped to the side of face than removed after the procedure upon recovery. So if the tooth accidentally dislodged despite the utmost care by anesthesiologist, it may not fall into the pharynx, trachea, or esophagus as it is tied to the string which had been taped securely to the patient face.

\section{Conclusion}

Perioperative dental damage and more so the dislodgement of the loose tooth is one of the most common adverse events during anaesthesia in oral surgeries. So preanesthetic assessment of dental condition of patient with proper recording can prevent perioperative dental damage and post operative claims by patients. In this article we have reported the successful retrieval of dislodged tooth during oral surgery (hemiglossectomy) done under general anaesthesia and highlighted the utility of simple method of using suction catheter instead of waiting and arranging fiber optic scope and fluoroscopy in locating dislodged tooth. Further our report reaffirms the need for exercising sufficient care in difficult intubation and surgeries in and around mouth with poor dental condition scenario to avoid dental injury.

\section{References}

1. Sriganesh Kamath, Madhusudhan Reddy, Dhaval Shukla (2011) Dislodgement of loose tooth and its recovery during difficult intubation. J Anaesth clin Pharmacol 27(1): 128-145.

2. PHK KoK, KM Kwon, C K Koay (2001) A case report of a fractured healthy tooth during use of gudeloropharyngeal airway. singapore Med J 42 (7): 322-324.

3. Steve Neustein, Mark Beicke (2007) Ingection of fixed partial denture during general anaesthesia. Anaesth Prog 54 (2): 50-51.

4. Morris J Nicholson (1965) Endobronchial aspiration of a tooth an unusual anaesthetic complication. Anaesthesia \& Analgesia 44(3).

5. Monaca E, Fock N, Doehn M, Wappler F (2007) The effectiveness of preformed tooth protectors during endotracheal intubation: An upper jaw model. Anaesthesia \& Analgesia 105(5): 1326-1332

6. Domino KB, Posner KL, Caplan RA, Cheney FW (1999) Airway injury during anaesthesia. Anaesthesiology 91(6): 1703-1711.

7. Yasny JS (2009) Perioperative dental considerations for the Anaesthesiologist. Anaesthesia \& Analgesia 108(5): 1564-1573.

\section{Your next submission with Juniper Publishers} will reach you the below assets

- Quality Editorial service

- Swift Peer Review

- Reprints availability

- E-prints Service

- Manuscript Podcast for convenient understanding

- Global attainment for your research

- Manuscript accessibility in different formats ( Pdf, E-pub, Full Text, Audio)

- Unceasing customer service

\section{Track the below URL for one-step submission}

https://juniperpublishers.com/online-submission.php 